\title{
Addison's disease, hypertension, renal and hepatic microthrombosis in 'primary' antiphospholipid syndrome
}

\author{
Sohail Inam ${ }^{1}$, Kamla Sidki², Abdul-Rahman Al-Marshedy ${ }^{3}$ and Roman \\ Judzewitsch ${ }^{1}$
}

\author{
'Division of Endocrinology, Department of Medicine, ${ }^{2}$ Department of Pathology and ${ }^{3}$ Department of \\ Paediatrics, Riyadh Armed Forces Hospital, Riyadh, Saudia Arabia.
}

\begin{abstract}
Summary: We describe a 14 year old boy with antiphospholipid syndrome who initially presented at the age of 10 with recurrent loin pain, fever, weight loss, leucocytosis, thrombocytopenia, hypertension and haematuria. He had primary adrenal insufficiency with bilaterally enlarged adrenals on computed tomographic (CT) scan consistent with adrenal infarction. Renal and liver biopsies showed microthrombi in the glomerular capillaries and hepatic sinusoids respectively. The case is unusual in that hypertension rather than hypotension was dominant and a CT scan was consistent with bilateral adrenal infarction without haemorrhage. He represented with evidence of persistent hypertension with glomerulosclerosis and glomerular microthrombi on repeat renal biopsy. He continues to have permanent adrenal insufficiency with complete atrophy of his adrenals.
\end{abstract}

\section{Introduction}

The lupus anticoagulant belongs to a family of antibodies directed against phospholipid. ${ }^{1}$ Patients who exhibit these antiphospholipid antibodies may be afflicted with arterial and venous thrombosis, thrombocytopenia, recurrent abortion and neurological manifestations, as well as haemolytic anaemia, pulmonary emboli, labile and accelerated hypertension, valvular heart disease, and skin lesions such as livedo reticularis. ${ }^{2-7}$ The combination of venous and arterial occlusive events, often with thrombocytopenia, in the presence of antiphospholipid antibodies is termed antiphospholipid syndrome. ${ }^{7}$

We describe a patient with antiphospholipid syndrome who presented with the unusual and confusing combination of adrenal insufficiency and hypertension, in whom Addison's disease was due to adrenal infarction documented by a computed tomographic (CT) scan at presentation. Although there are several reports ${ }^{8-14}$ of the rare association of Addison's disease and the lupus anticoagulant, enlarged adrenals on CT scan without haemorrhage have not been previously described.

Correspondence: S. Inam, M.R.C.P. D-175, Riyadh Armed Forces Hospital, P.O. Box 7897, Riyadh 11159, Saudia Arabia.

Accepted: 29 October 1990

\section{Case report}

A boy first presented in January 1986 at the age of 10 with a 4-week history of recurrent abdominal pain, $5 \mathrm{~kg}$ weight loss, vomiting and fever. He weighed $20 \mathrm{~kg}$, temperature $38^{\circ} \mathrm{C}$, blood pressure $127 / 79 \mathrm{mmHg}$. There was a systolic murmur at the mitral area, with bilateral loin tenderness and hepatomegaly. Urinalysis showed blood +++ , white cell count $13 \times 10^{9} / 1$ with neutrophil leucocytosis, haemoglobin $10 \mathrm{~g} / \mathrm{dl}$, platelets $90 \times 10^{9} / 1$ and ESR $126 \mathrm{~mm} / 1 \mathrm{st} \mathrm{h}$. Blood films showed no fragmented red blood cells. Biochemical profile was normal. Blood, throat, urine and stool cultures were negative, as were stools for ova and parasites. Mantoux test was negative. X-rays of chest, abdomen and an abdominal ultrasound were normal. Urine showed a few cell casts. ANA and anti-DNA were negative; complement $\mathrm{C} 3$ and $\mathrm{C} 4$ normal. Twenty-four hour urine: protein $250 \mathrm{mg}$ / day, 4-hydroxy-3-methoxy mandelic acid (HMMA) $10.1 \mu \mathrm{mol} /$ day (N 16-50). PT 14 seconds (control 14), PTT 58 seconds (control 30), fibrinogen $4.5 \mathrm{~g} / \mathrm{l}$. No excess fibrinogen degradation products. Lupus anticoagulant + ve (measured by the platelet neutralization procedure). ${ }^{15}$

Four days later the patient had lost a further $2 \mathrm{~kg}$ and his blood pressure was $135-150 / 95 \mathrm{mmHg}$. He became confused with no localizing neurological signs and was commenced on intravenous hydralazine. The same night his serum sodium was $116 \mathrm{mmol} / 1$, and potassium $4.5 \mathrm{mmol} / \mathrm{l}$; spot urine 
sample showed a serum sodium level of $180 \mathrm{mmol} / 1$ and osmolality $781 \mathrm{mosmol} / \mathrm{kg}$. A tetracosactrin (synacthen) stimulation test was performed: basal cortisol $33 \mathrm{nmol} / 1$, at $60 \mathrm{~min} 33.4 \mathrm{nmol} / 1$. A long synacthen test gave a cortisol value of $137 \mathrm{nmol} / \mathrm{l}$, confirming primary adrenal insufficiency. Serum aldosterone was undetectable in the face of a high renin level. Thyroid function was normal and thyroid antibodies were negative. A CT scan of his abdomen (Figure 1) showed bilaterally enlarged hypodense adrenals with no contrast enhancement consistent with adrenal infarction. Both kidneys were enlarged with abnormal contrast enhancement, also consistent with areas of infarction (Figure 2). Renal biopsy showed segmental mesangioproliferative glomerulonephritis with fibrin thrombi in glomerular capillaries. Liver biopsy showed zonal necrosis and haemorrhage with fibrin thrombi in sinusoids and portal vessels. A bone marrow examination was normal, including culture for myobacteria. After commencement on intravenous hydrocortisone, $100 \mathrm{mg}$ every $6 \mathrm{~h}$, within $24 \mathrm{~h}$ his serum sodium was $134 \mathrm{mmol} / \mathrm{l}$. His fever settled, he improved and his blood pressure returned to normal. He required hydrocortisone $15 \mathrm{mg} /$ day and fludrocortisone $100 \mu \mathrm{g}$ daily for adequate adrenal replacement, as gauged by his electrolytes. In August 1987 a repeat synacthen stimulation test showed no cortisol response.

He represented in December 1989 with loin pain and headache, and blood pressure 170/140 $\mathrm{mmHg}$. He had a forceful apex beat with a mid-systolic murmur at the mitral area. The left loin was tender and fundi normal. Urine showed no RBC or casts. Chest X-ray showed cardiomegaly, the electrocardiogram left ventricular hypertrophy. Echocardiogram showed mitral regurgitation with prolapse of anterior mitral leaflet; left ventricular mass $178 \mathrm{~g} / \mathrm{m}^{2}$ (N 76-108). Haemogram and biochemical profile were normal. Twenty-four hour urine: HMMA again normal, VDRL + ve, TPHA and FTA - ve. PTT 67 seconds (control 36), lupus anticoagulant + ve. Facilities for anticardiolipin antibodies were not available. ANA 1:40, anti-DNA $18(\mathbf{N}<7)$. Complement normal. Magnetic resonance imaging (MRI) of adrenals showed complete atrophy. A long synacthen test showed no response. Fludrocortisone was stopped but hypertension persisted and required captopril $150 \mathrm{mg}$ /day for control. Renal angiogram was normal. Repeat renal biopsy was similar to that in January 1986 except for glomerular sclerosis; again there was no evidence of arteritis. Electron microscopy showed mesangial cell proliferation but no evidence of immune complex deposition. Skin biopsy for lupus band was negative. A diagnosis of the antiphospholipid syndrome was made and the patient has since been maintained on warfarin.

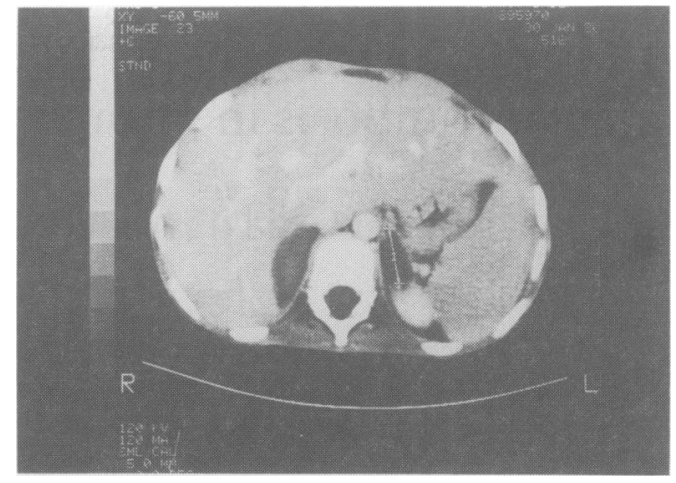

Figure 1 Contrast-enhanced CT scan of the adrenals showing bilaterally enlarged adrenals of low intensity with no enhancement.

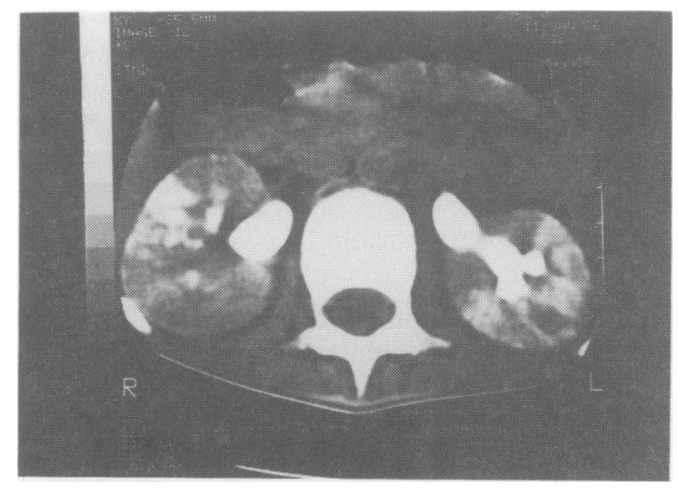

Figure 2 Contrast-enhanced CT scan of the kidneys showing bilaterally enlarged kidneys with abnormal contrast distribution consistent with areas of infarction.

\section{Discussion}

Adrenal insufficiency related to antiphospholipid syndrome is rare, the postulated mechanisms being bilateral adrenal venous thrombosis and/or haemorrhage. ${ }^{8,9,11,16}$ The propensity of the adrenals for this vasculopathy results from the particular vasclar arrangement referred to as a 'vascular dam, ${ }^{17,18}$ Fibrin thrombi in the small vascular channels of the adrenals without vasculitis have been observed at histology in some of these patients. ${ }^{12,13}$ Our patient showed features compatible with bilateral adrenal vein thrombosis on CT scan. He was too sick to perform an adrenal venogram. There were no features or family history of autoimmune disease and large adrenals (especially of this size) on CT scan are not a feature of autoimmune adrenalitis. The density of the adrenals on CT scan was not suggestive of adrenal haemorrhage, and the other causes of large adrenals such as tuberculosis, sarcoidosis, amyloidosis and malignancy were 
either excluded or not applicable. In cases of adrenal insufficiency in 'primary' antiphospholipid syndrome where adrenal imaging has been performed early it has shown adrenal haemorrhage. ${ }^{11-13}$ Ours is the only case to our knowledge where adrenal imaging (performed within $24 \mathrm{~h}$ of the onset of hyponatraemia) showed large adrenals without haemorrhage.

About half the cases of antiphospholipid antibodies occur in association with systemic lupus erythematosus (SLE) ${ }^{4,7,9}$ Many patients with antiphospholipid antibodies have a low titre of ANA but do not fit the criteria of the American Rheumatology Association (ARA) for the diagnosis of SLE. ${ }^{7,18,19}$ In SLE the adrenals are usually normal at autopsy and Addison's disease is extremely rare and related to a vascular insult. ${ }^{9}$ Our patient does not fit the ARA criteria for SLE, although his anti-DNA titre was slightly raised on the last presentation. Interference with anti-DNA estimation by antiphospholipid antibody is recognized and a matter of debate, with interference found by some ${ }^{20}$ and not others. ${ }^{21}$ The renal biopsy also showed no immune complex deposition, and we feel our patient belongs to the 'primary' antiphospholipid syndrome, although he may develop SLE subsequently.

Our patient is also unique in that he had hypertension at the time that he developed adrenal insufficiency. This has not been reported previously and is likely to confuse the diagnosis of adrenal insufficiency. This high-renin low-aldosterone hypertension was the result of concomitant renal involvement as evidenced by haematuria, CT scan appearance of the kidneys and histology. The HMMA results were repeatedly low, suggesting that the adrenal medulla was also affected. Fibrin microthrombi in the glomeruli have been described in association with antiphospholipid antibodies. ${ }^{4,22}$ In patients with SLE fibrin microthrombi are much more likely to occur in the presence of antiphospholipid antibodies. ${ }^{23,24}$ Infarction of the kidneys and liver has also been recognized with this syndrome. ${ }^{3,25}$ Interestingly, in our patient both the liver and renal histology showed microthrombi and infarction.

Hypertension, both labile and accelerated, has been reported with the antiphospholipid anti-

\section{References}

1. Harris, E.N., Asherson, R.A. \& Hughes, G.R.V. Antiphospholipid antibodies-autoantibodies with a difference. Ann Rev Med 1988, 39: 261-271.

2. Hughes, G.R.V. Thrombosis, abortion, cerebral disease and the lupus anticoagulant. $\mathrm{Br} \mathrm{Med} J$ 1983, 287: 1088-1089.

3. Asherson, R.A. \& Harris, E.N. Anticardiolipin antibodies: clinical associations. Postgrad Med J 1986, 62: 1081-1087.

4. Bingley, P.J. \& Hoffbrand, B.I. Antiphospholipid antibody syndrome: a review. J $R$ Soc Med 1987, 80: 445-448. bodies. $^{3,7}$ The electrocardiogram, chest X-ray and echocardiogram in our patient were consistent with persistent hypertension. Although fludrocortisone therapy may have aggravated his hypertension, the persistence of hypertension several weeks after stopping therapy with this drug indicates an alternative cause. We excluded renal artery stenosis as a cause for hypertension in our patient, as has been reported previously. ${ }^{7}$ Abnormalities on renal biopsy may persist for years in women with recurrent abortions and antiphospholipid syndrome. ${ }^{22}$ Further, patients with microthrombi on renal biopsy are more likely to get glomerular sclerosis and thus develop persistent hypertension. ${ }^{23}$ Both these features were confirmed on repeat renal biopsy in our patient.

All other features of our patient, including the recurrent abdominal pain, high ESR, thrombocytopenia, anaemia and false-positive VDRL, are seen in this syndrome. ${ }^{3-5,7}$ Valvular heart disease, including mitral regurgitation, has also been associated with antiphospholipid antibodies. ${ }^{7.26}$ Another peculiarity found was a persistently high amoeba titre of 1:2046, 4 years after adequate treatment with metronidazole in an area not endemic for amoebiasis. This result may represent an interference in the assay by the antiphospholipid antibody not previously reported.

We have presented a case of antiphospholipid syndrome who presented with abdominal pain, fever, thrombocytopenia, anaemia, haematuria and hypertension. He was found to have adrenal insufficiency, with large adrenals on CT scan consistent with adrenal infarction. Renal and liver biopsies showed fibrin microthrombi. The case is unique in that hypertension rather than hypotension was dominant at onset of adrenal insufficiency and is the first reported case where enlarged adrenals were not due to haemorrhage on CT scan at presentation.

\section{Acknowledgements}

We are grateful to Dr Mohammed Sulaiman and Dr Mona Al-Shahed for their assistance and valued comments.

5. Hughes, G.R.V., Asherson, R.A. \& Khamashta, M.A. Antiphospholipid syndrome: linking many specialties. Ann Rheum Dis 1989, 48: 355-356.

6. Sontheimer, R.D. The anticardiolipin syndrome: a new way to slice an old pie, or a new pie to slice? Arch Dermatol 1987, 123: $590-595$.

7. Asherson, R.A., Khamashta, M.A., Ordi-Ros, J. et al. The 'primary' antiphospholipid syndrome: major clinical and serological features. Medicine 1989, 68: 366-374. 
8. Carette, S. \& Jobin, F. Acute adrenal insufficiency as a manifestation of the anticardiolipin syndrome? Ann Rheum Dis 1989, 48: 430-431.

9. Asherson, R.A. \& Hughes, G.R.V. Recurrent deep vein thrombosis and Addison's disease in 'primary' antiphospholipid syndrome. J Rheumatol 1989, 16: 378-380.

10. Pelkonen, P., Cimello, O., Rasi, V. \& Varaala, O. Venous thrombosis associated with lupus anticoagulant and anticardiolipin antibodies. Acta Paediatr Scand 1988, 77: 767-772.

11. Walz, B., Kong, H.H.P. \& Silver, R. Adrenal failure and the primary antiphospholipid syndrome. $J$ Rheumatol 1990, 17: 836-837.

12. Yap, A.S., Powell, E.E., Yelland, C.E., Mortimer, R.H. \& Perry-Keene, D.A. Lupus anticoagulant: letter. Ann Intern Med 1989, 111: 262-263.

13. Alperin, N., Babu, S. \& Weinstein, A. Acute adrenal insufficiency and the antiphospholipid syndrome: letter. Ann Intern Med 1989, 111: 950.

14. Rose, C.D. \& Goldsmith, D.P. Childhood adrenal insuffciency, chorea and antiphospholipid antibodies: letter. Ann Rheum Dis 1990, 41: 421-422.

15. Triplett, D.A., Brandt, J.T., Kaczor, D. \& Schaeffer, J. Laboratory diagnosis of lupus inhibitors: a comparison of the tissue thromboplastin inhibition procedure with a new platelet neutralization procedure. Am J Clin Pathol 1983, 79: 678-682.

16. Asherson, R.A. \& Hughes, G.R.V. Addison's disease and primary antiphospholipid syndrome: letter. Lancet 1989, ii: 874.

17. Symington, T. The adrenal cortex. In: Bloodworth, J.B. Jr (ed.) Endocrine Pathology: General and Surgical, 2nd ed. Williams and Wilkins, Baltimore, 1982, pp. 419-471.
18. Rao, R.H., Vagnucci, A.H. \& Amico, J.A. Bilateral massive adrenal haemorrhage: early recognition and treatment. Ann Intern Med 1989, 110: 227-235.

19. Harris, E.N., Gharavi, A.E. \& Hughes, G.R.V. Anti-phospholipid antibodies. Clin Rheum Dis 1985, 11: 591-609.

20. Lafer, E.M., Rauch, J., Andrzejewski, C. et al. Polyspecific monoclonal lupus antibodies reactive with both polynucleotides and phospholipids. J Exp Med 1981, 153: 897-909.

21. Harris, E.N., Gharavi, A.E., Boey, M.L. et al. Anticardiolipin antibodies: detection by radioimmunoassay and association with thrombosis in systemic erythematosus. Lancet 1983, ii: $1211-1214$.

22. Kincaid-Smith, P., Fairley, K.F. \& Kloss, M. Lupus anticoagulant associated with renal thrombotic microangiopathy and pregnancy related renal failure. $Q J \mathrm{Med}$ 1988, 69: 795-815.

23. Kant, K.S., Pollak, V.E., Weiss, M.A., Glueck, H.I., Miller, M.A. \& Hess, E.V. Glomerular thrombosis in systemic lupus erythematosus: prevalence and significance. Medicine 1981, 60: $71-86$.

24. Glueck, H.I., Kant, K.S., Weiss, M.A. et al. Thrombosis in systemic lupus erythematosus: relation to the presence of circulating anticoagulant. Arch Intern Med 1985, 145: 1389-1395.

25. Asherson, R.A., Hughes, G.R.V. \& Derksen, R.H.W.M. Renal infarction associated with antiphospholipid antibodies in systemic lupus erythematosus and 'lupus like' disease: letter. J Urol 1988, 140: 1028.

26. Khamashta, M.A., Cervera, R., Asherson, R.A. et al. Association of antibodies against phospholipids with heart valve disease in systemic lupus erythematosus. Lancet 1990, 335: $1541-1544$ 